\title{
$\quad 000-2223-25$
}

A PROGRESS REPORT

to the

U. S. ENERGY RESEARCH AND DEVELOPMENT ADMINISTRATION

\section{SPIN LABEL STUDIES ON MEMBRANES AND THE AQUEOUS ZONES OF MEMBRANE ENCLOSURES}

Submitted by Alec D. Keith, Principal Investigator

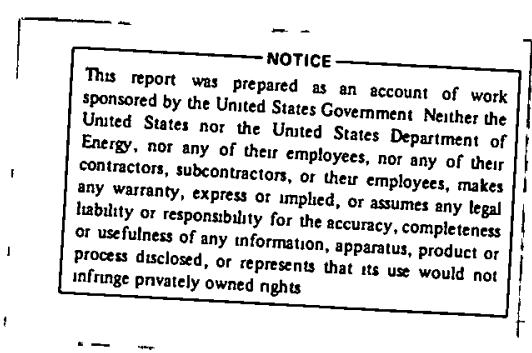

Period Covered: August, 1976 to the present

Department of Biochemistry \& Biophysics The Pennsylvania State University University Park, PA 16802

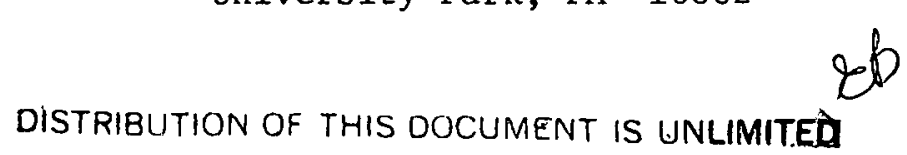

August, 1977 


\section{DISCLAIMER}

This report was prepared as an account of work sponsored by an agency of the United States Government. Neither the United States Government nor any agency Thereof, nor any of their employees, makes any warranty, express or implied, or assumes any legal liability or responsibility for the accuracy, completeness, or usefulness of any information, apparatus, product, or process disclosed, or represents that its use would not infringe privately owned rights. Reference herein to any specific commercial product, process, or service by trade name, trademark, manufacturer, or otherwise does not necessarily constitute or imply its endorsement, recommendation, or favoring by the United States Government or any agency thereof. The views and opinions of authors expressed herein do not necessarily state or reflect those of the United States Government or any agency thereof. 


\section{DISCLAIMER}

Portions of this document may be illegible in electronic image products. Images are produced from the best available original document. 
ABSTRACT

The feasibility of measuring properties of the aqueous cytoplasm with spin labels is established. The parameters of protected aqueous cell volume, restriction of rotational motion of probe molecules, and limitations placed on translational diffusion of probe molecules by the aqueous cytoplasm are described.

A class of spin labels called surface spin labels, designed to probe charge and other surface properties of membranes is described. These spin labels have undergone initial characterization, and in yeast cells it has been confirmed that essentially all of the spin label signal can be isolated to the cell surface.

\section{NOTICE}

This report was prepared as an account of work sponsored by the United States Government. Neither the United States nor the United States Energy Research and Development Administration nor any of their employees, nor any of their contractors, subcontractors, or their employees, makes any warranty, express or implied, or assumes any legal liability or responsibility for the accuracy, completeness, or usefulness of any information, apparatus, product or process disclosed or represents that its use would not infringe privately owned rights. 
PROGRESS REPORT

A complete bibliography for the principal investigator is included in the present progress report and reference numbers from this bibliography are used for convenience. The progress report deals with two types of spin label probe experiments. Type 1 probes the cytoplasmic space and type 2 is aimed at probing cell surfaces or the surfaces of phospholipid vesicle structures. Usually spin label experiments employing the more commonly used membrane probes such as spin label fatty acids, spin label sterols, and spin label hydrocarbons are also carried out in parallel experiments for purposes of comparison and to place these newer approaches in perspective to the existing literature.

\section{Aqueous Zones of Membrane Enclosures}

The approach of studying cellular cytoplasm or the aqueous phase of vesicle enclosures with spin labels was initiated with Ref. 46 and was put to further use in Refs. 58 and 61 . These papers have been covered in the previous progress reports. This general approach requires that the spin label signal be removed from zones exterior to the membrane enclosure by a spin-broadening agent and at the same time that the membrane be impermeable to the spin-broadening agent. The spin label must be capable of penetrating the membrane or some other condition must be affected to allow the spin label to enter the membrane enclosure. The spin-broadening agent removes the spin label signal by lowering the amplitude of the signal so that the unaffected signal originating from the membrane interior now dominates. This procedure allows the properties of the aqueous cytoplasm to be probed. This approach can also be used to study spin label signals originating 
from membranes other than the part of the membrane exposed to the surface.

In Ref. 67 this general procedure was used to measure cold damage to sperm cells. Sperm are sensitive to cold shock at temperatures above the ice point. This procedure allowed the evaluations of chemicals suspected of being cryoprotectants of sperm cells. This research continues in an on-going collaboration with Prof. Roy Hammerstedt of the biochemistry section of our department.

In Ref. 68 yeast cell mutants deficient in synthesis of saturated fatty acids were shown to increase in cytoplasmic viscosity as determined by an increase in the restriction to rotational diffusion of water-soluble spin labels. These cells showed modified properties of cytoplasmic zones. Parallel experiments carried out with membrane hydrocarbon-soluble probes revealed that no detectable changes occurred in the hydrocarbon phase of membranes.

Ref. 72 presented a similar study using a yeast auxotroph for inositol. This mutant is deficient in inositol synthesis and requires inositol for growth. The inositol is used in the biosynthesis of phosphatidyl inositol and is probably required for membrane synthesis. The experimental results are similar to the experiment presented in the above paragraph in that starvation for inositol modified cytoplasmic properties but membrane properties were unaffected as detected with the same kind of spin labels presented above.

In Ref. 81 sperm cells were analyzed using appropriate conditions to measure properties of cytoplasm. In this study the aqueous volume of the cytoplasm was measured as a function of osmotic strength (method explained in the accompanying appendix). The rotational diffusion of a small watersoluble spin label was also measured. The spin exchange frequency was 
measured under the same conditions as those by which the rotational motion measurements were made (method explained in the appendix). These latter two parameters allow a direct comparison between rotational and translational diffusion properties of sperm cell cytoplasm. Rotational diffusion is a measure of the forces limiting molecular motion over short dimensions whereas translational diffusion, as measured by collision frequency of spin label molecules that are in static equilibrium, measures the forces restricting diffusion over larger dimensions. The larger dimension is on the order of the cubic lattice spacing existing between spin label molecules in solution. The actual mean free path of the spin label required for collisions is considerably larger than the average cubic lattice spacing calculated from the known molarity. These considerations are dealt with in the accompanying appendix together with the related equations that are required to put these types of data into a quantitative treatment.

The approach of measuring properties of the cytoplasm with respect to enclosed volume allows cell size to be measured by a quick, accurate and easy method. Rotational motion is measured by conventional means that a variety of experimenters including ourselves have used over a period of years. Translational diffusion measurements are made possible on a relatively accurate quantitative scale by the treatment presented in Ref. 77. The information in this paper represents work over a $4 \frac{1}{2}$ year period in which our laboratory was concerned with characterizing spectral parameters relating to electron spin exchange. As a consequence of this work we have developed the use of deuterated spin labels which in turn allow lower concentrations of spin-broadening agents to be used. Lower concentrations of the ionic spin-broadening agents is important in regard to the maintenance 
of controlled osmotic conditions. The information presented in Ref. 79 is a chapter for a book entitled The Aqueous Cytoplasm which is the outgrowth of a conference held at Penn State a few years ago on the physical properties of aqueous cytoplasm. This chapter puts together our entire approach on the subject and summarizes the current state of progress.

II. The Use of Membrane-Directed Surface Labels

Spin-labeled phospholipids have been used in sophisticated experiments carried out by McConnell and coworkers. These experiments were aimed at measuring the rate at which phospholipid molecules cross membranes. Several other experiments have been presented by a number of authors using spinlabeled phospholipids for varying purposes. Spin-labeled phospholipids appear to be very effective and are well designed probes for certain purposes. We first tried spin-labeled phospholipids for the purpose of measuring the surface properties of cells and membrane vesicles. Under the conditions of our experiments and for our purposes we were unsuccessful in detecting modification of the signals of spin-labeled phospholipids induced by adding foreign molecules or perturbation conditions to the membranes that were so treated. As a consequence of the inability to measure modified properties of membranes by the use of spin-labeled phospholipids we constructed a different type of spin label also designed to localize on membrane surfaces. An initial report describing the use of such spin labels is presented in Ref. 64. In this report we describe the use of surface spin labels. In carrying out this characterization, we used spin-labeled TEMPONE (a sma11 water-soluble and membrane-permeable probe) to measure the cytoplasmic interior of the same yeast cells. Such simultaneous measurements make it possible to determine how much of the signal from the cell surface could 
be removed while maintaining the integrity of the spin label signal emanating from the cellular cytoplasm. Such an experiment verifies that the spinbroadening agent is incapable of penetrating yeast cells. Since that experiment was carried out the same type of experiment has been repeated in our laboratory using ${ }^{15} \mathrm{~N}$ water-soluble spin labels and ${ }^{14} \mathrm{~N}$ surface labels. Under these conditions and in the same cells it is possible to remove the surface spin label signal and retain the signal originating from the cellular cytoplasm, proving that spin-broadening agents only remove signal from the cell surface and zones exterior to the cell.

As we continued this approach and carried out experiments on mammalian cells we found that not as much of the cell surface signal could be removed. Ref. 84 represents an extensive experiment which took place over a period of two years and in which sperm cells were treated with both a negatively and a positively charged surface label in an attempt to measure the properties of the sperm membrane surface. In order to obtain a maximum amount of information from these experiments, we simultaneously used negative and positive aliphatic detergent molecules to further modify the charge. By comparing the spin label signals from two different types of sperm it was possible to detect a substantial difference in surface charge properties. We have now extended these experiments to include those of model membrane systems both in multilayer structures and in enclosed vesicles. As an example of results from our current experiments we have used dimyristoyl lecithin (DML) as a vesicle matrix and have added varying quantities of phosphatidyl serine or phosphatidyl isositol to these vesicles. Adding increasing quantities of phosphatidyl serine causes increasing quantities of the negatively charged surface label to be localized in the aqueous phase of the vesicle dispersion. 
The negatively charged surface labels which we have synthesized often show a partitioning of the spin label signal between aqueous zones and membrane-associated zones. Increasing the quantity of a negatively charged phospholipid associated with these DML vesicles causes increasing quantities of the signal to be associated with the aqueous phase until by the time $20 \%$ of the phospholipid in the vesicles is negatively charged, essentially all of the negatively charged spin label is localized in the aqueous phase. These data indicate that charge repulsion is an important force which makes It possible to measure local charge effects on membrane surfaces. By carefully observing the spin label signal of such probes we believe it will be possible to measure important properties of membrane surfaces. 

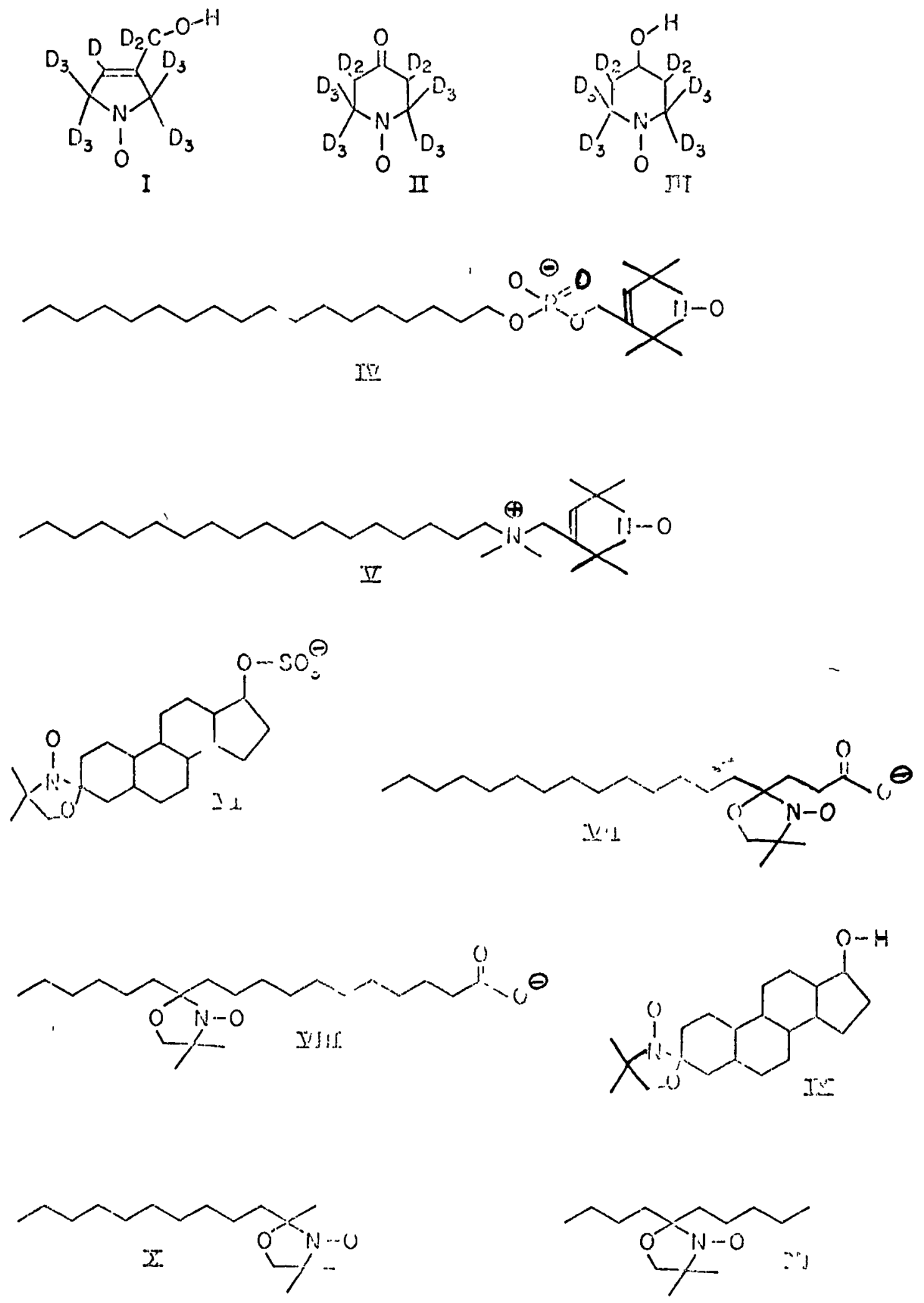
I wat a small agrarian community, on the My family moved to Phoenix, Arizona, in 1942, where I graduated from high school in 1950. From January 1951-1954 I served in the U.S. Air Force. I spent 1954-1957 in military and VA hospitals (polio). I attended Long Beach State College from 1959-1962 obtaining a B.S. degree, and the University of Oregon from 1962-1966 earning a $\mathrm{Ph} . \mathrm{D}$. in genetics. My course work in both graduate and undergraduate education was evenly balanced between biology and chemistry. From June 1966 through July 1967 I was a postdoctoral fellow in the laboratory of Edward Novitski (Oregon) where I spent about half my time collaborating with Professor Hayes Griffith (Chemistry, Oregon) on problems dealing with the development of spin labeled lipids. In 1967 I accepted an appointment in the Genetics Department at the University of California at Berkeley. In 1972 I accepted an appointment in the Biophysics Department (now Department of Biochemistry and Biophysics) of the Pennsylvania State University where $I$ am continuing a teaching-research career. I have taught a variety of courses ranging from biochemical genetics to a core sequence in biophysics.

1976$1972-$ 1976 $1967-$ 1972 $1966-$ 1967 1966 $1962-$ 1966 1962
Professor of Biophysics, The Pennsylvania State University Associate Professor of Biophysics, The Pennsylvania State University, University Park, Pennsylvania Assistant Professor of Genetics, University of California, Berkeley

U.S. Public Health Service Postdoctoral Fellow, University of Oregon, Eugene

Ph.D., University of Oregon

U.S. Public Health Service Predoctoral Fellowship University of Oregon

B.S., Long Beach State College, Long Beach, California 


\section{BIBLIOGRAPHY}

1. Keith, A. D. Analysis of the lipids in Drosophila melanogaster. Comp. Biochem. Physio1. 17:1127-1136 (1966).

2. Keith, A. D. Fatty acid metabolism in Drosophila melanogaster: Formation of palmitoleate. Life Sci. 6:213-218 (1967).

3. Keith, A. D. Fatty acid metabolism in Drosophila melanogaster: Interaction between dietary fatty acids and de novo synthesis. Comp. Biochem. Physiol. 21:587-600 (1967).

4. Keith, A. D., G. Gauslea and B. S. Anderson. In vitro biosynthesis of fatty acids in Drosophila melanogaster. Lipids 2:429-431 (1967).

5. Johnson, M. P., A. D. Keith and P. R. Ehrlich. The population biology of the butterfly Euphydryas editha. VII. Has E. editha evolved a serpentine race? Evolution 22:422-423 (1967).

6. Goldin, H. H. and A. D. Keith. Fatty acid biosynthesis by isolated mitochondria from Drosophila melanogaster. J. Insect Physiol. 14:887-899 (1968).

7. Waggoner, A. S., A. D. Keith and O. H. Griffith. Electron spin resonance of solubilized long-chain nitroxides. J. Phys. Chem. 72:4129-4132 (1968).

8. Keith, A. D., A. S. Waggoner and 0. H. Griffith. Spin-labeled mitochondrial lipids in Neurospora crassa. Proc. Nat1. Acad. Sci. U.S. 61:819-826 (1968).

9. Keith, A. D., M. R. Resnick and A. B. Haley. Fatty acid desaturase mutants of Saccharomyces cerevisiae. J. Bacteriol. 98:415-420 (1969).

10. Waggoner, A. S., T. J. Kingzett, S. Rottschaefer, O. H. Griffith and A. D. Keith. A spin-labeled lipid for probing biological membranes. Chem. Phys. Lipids 3:245-253 (1969).

11. Snipes, W. and A. D. Keith. Spin labels: New biological applications for ESR. Res. \& Deve1. 21:22-26 (1970).

12. Wisnieski, B. J., A. D. Keith and M. R. Resnick. Double bond requirement in a fatty acid desaturase mutant of Saccharomyces cerevisiae. J. Bacteriol. 101:160-165 (1970).

13. Keith, A. D., G. Bulfield and W. Snipes. Spin-labeled Neurospora mitochondria. Biophys. J. 10:618-629 (1970).

14. Tourtellotte, M. E., D. Branton and A. D. Keith. Membrane structure: Spin labeling and freeze-etching of Mycoplasma laidlawii. Proc. Nat1. Acad. Sci. U.S. $66: 909-916$ (1970).

15. Kiyomoto, R. K. and A. D. Keith. Fatty acid metabolism in Drosophila melanogaster. II. Metabolic origin of monoenes. Lipids 5:617-620 (1970).

16. Keith, A. D. Chemical induction of mutagenesis and carcinogenesis, in Sixth Berkeley Symposium on Mathematical Statistics and Probability (ed. L. Neyman and E. L. Scott). U. California Press, 1970. pp. 383-391.

17. Raison, J. K., J. M. Lyons, R. J. Mehlhorn and A. D. Keith. Temperature induced phase changes in mitochondrial membranes detected by spin labeling. J. Biol. Chem. 246:4036-4040 (1971).

18-23 Several short articles 
Keith - Bibliography (cont'd)

24. Henry, S. A. and A. D. Keith. Saturated fatty acid requirer of Neurospora crassa. J. Bacterio1. 106:174-182 (1971).

25. Williams, J. C., R. J. Mehlhorn and A. D. Keith. Novel syntheses and biological uses of spin labels. Chem. Phys. Lipids 7:207-230 (1971).

26. Henry, S. A. and A. D. Keith. Membrane properties of a saturated fatty acid requirer of yeast revealed by spin labels. Chem. Phys. Lipids 7: 245-265 (1971).

27. Eletr, S. and A. D. Keith. Spin-labeled studies of lipid alkyl chain dynamics in biological membranes: Role of unsaturated sites. Proc. Natl. Acad. Sci. U.S . 69:1353-1357 (1972).

28. Tinoco, J., D. Ghosh and A. D. Keith. Interactions of spin-labeled lipid molecules with natural lipids in monolayers at the air-water interface. Biochim. Biophys. Acta (Biomembranes) 274:279-285 (1972).

29. Williams, M. A., R. C. Stancliff, L. Packer and A. D. Keith. Relation of unsaturated fatty acid composition of rat-liver mitochondria to oscillatory, spin label motion, permeability, and oxidative phosphorylation. Biochim. Biophys. Acta 267:444-456 (1972).

30. Keith, A. D. and R. J. Mehlhorn. Spin label studies in biological membranes. Chem. Phys. Lipids 8:314-317 (1972).

31. James, R., D. Branton, B. J. Wisnieski and A. D. Keith. Composition, structure and phase transitions in yeast fatty acid auxotrophs: Spin labels and freeze-fracture. J. Supramolec. Struc. 1:38-49 (1972).

32. Mehlhorn, R. J. and A. D. Keith. Spin labeling of biological membranes, in Membrane Molecular Biology (ed. C. F. Fox and A. D. Keith) Sinauer Associates, Inc., Stamford, CT, 1972. pp. 127-227.

33. Keith, A. D. and R. J. Mehlhorn. Membrane lipid structure as revealed by X-ray diffraction. Ibid., pp. 117-122.

34. Fox, C. F. and A. D. Keith (eds.) Membrane Molecular Biology. Sinauer Associates, Inc., Stamford, CT, 1972. 525 pp.

35. Zimmer, G., A. D. Keith and L. Packer. Effect of sucrose and uncouplers on lipid spin labeling of mitochondria. Arch. Biochem. Biophys. 152: 105-113 (1972).

36. Tinberg, H. M., L. Packer and A. D. Keith. Role of lipids in mitochondrial energy coupling - evidence from spin labeling and freeze-fracture electron microscopy. Biochim. Biophys. Acta 283:193-205 (1972).

37. Kroes, J., R. Ostwald and A. D. Keith. Lipid-protein interaction in RBC membranes of cholesterol fed guinea pigs using spin labels. Biochim. Biophys. Acta 274:71-74 (1972).

38. Keith, A. D., B. J. Wisnieski, S. A. Henry and J. C. Williams. Membranes of yeasts, in Lipids and Biomembranes of Eucaryotic Microorganisms

(ed. J. Erwin) Academic Press, 1973. pp. 259-321.

39. Keith, A. D., R. J. Mehlhorn, K. Freeman and A. V. Nichols. Spin labeled lipid probes in serum lipoproteins. Chem. Phys. Lipids 10:223-236 (1973). 
Keith - Bibliography (continued)

40. Williams, M. A., D. W. Taylor, J. Tinoco, M. A. Ojakian and A. D. Keith. Utilization of $\mathrm{C}_{20}$-polyunsaturated fatty acids by a yeast fatty acid desaturase mutant. Biochem. Biophys. Res. Comm. 54:1560-1566 (1973).

41. Mehlhorn, R. J., W. Snipes and A. D. Keith. Spin label motion in fatty acids. Biophys. J. 13:1223-1231 (1973).

42. Keith, A. D., M. Sharnoff and G. E. Cohn. A summary and evaluation of spin labels used as probes for biological membrane structure. Biochim. Biophys. Acta (Biomemb. Rev.) 300:379-419 (1973).

43. Linden, C. D., A. D. Keith and C. F. Fox. Correlations between fatty acid distribution in phospholipids and the temperature dependence of membrane physical state. J. Supramolec. Biol. 1:523-534 (1973).

44. Torres-Pereria, J., R. Mehlhorn, A. D. Keith and L. Packer. Changes in membrane lipid structure of illuminated chloroplasts - Studies with spinlabeled and freeze-fractured membranes. Arch. Biochem. Biophys. 160: 90-99 (1974).

45. Cohn, G., A. D. Keith and W. Snipes. Spin-label translational diffusion in solid tristearin. Biophys. J. 14:178-188 (1974).

46. Keith, A. D. and W. Snipes. Viscosity of cellular protoplasm. Science 183:666-667 (1974). Technical comment re 186:158-159 (1974).

47. Snipes, W., J. Cupp, J. Sands, A. Keith and A. Davis. Calcium requirement for assembly of the lipid-containing bacteriophage PM2. Biochim. Biophys . Acta (Biomembranes) 339:311-322 (1974).

48. Eletr, S., M. A. Williams, T. Watkins and A. D. Keith. Perturbations of the dynamics of lipid alkyl chains in membrane systems: Effect on the activity of membrane-bound enzymes. Biochim. Biophys. Acta 339:190-201 (1974).

49. Snipes, W., J. Cupp, G. Cohn and A. Keith. ESR analysis of the nitroxide spin label TEMPONE in single crystals of the reduced TEMPONE matrix. Biophys. J. 14:20-32 (1974).

50. Wade, N., R. W. Breidenbach, A. D. Keith and J. M. Lyons. Phase changes in castorbean mitochondria. J. Plant Physiol. 54:320-323 (1974).

51. Keith, A. D. and M. A. Williams. Yeast lipid mutants: Isolation, maintenance and spin label studies, in Methods of Enzymology, vol. XXXII, Part B (ed. S. Fleisher and L. Packer) Academic Press, 1974. pp. 819-837.

52. Keith, A. D., D. Horvat and W. Snipes. Spectral characterization of ${ }^{15} \mathrm{~N}$ spin labels. Chem. Phys. Lipids 13:49-62 (1974).

53. Snipes, W., A. Keith and P. Wanda. Active transport of choline by a marine pseudomonad. J. Bacteriol. 120:197-202 (1974).

54. Snipes, W., J. Douthwright, J. Sands and A. D. Keith. Control of phospholipid synthesis and viral assembly by bacteriophage PM2. Biochim. Biophys. Acta 363:340-350 (1974).

55. Sands, J. A., J. Cupp, A. Keith and W. Snipes. Temperature sensitivity of the assembly process of the enveloped bacteriophage $\phi 6$. Biochim. Biophys. Acta 373:277-285 (1974). 
Keith - Bibliography (continued)

56. Keith, A. D., D. Deamer and J. K. Raison. Biological membrane structure and function. Science, 188:282 (1975).

57. Lyons, J. M., A. D. Keith and I. J. Thomason. Temperature induced phase transitions in nematode lipids and their influence on respiration.

J. Nemato1. 7:98-104 (1975).

58. Morse, P. D. II, M. Ruhlig, W. Snipes and A. D. Keith. Viscosity profile of sarcoplasmic reticular vesicles. Arch. Biochem. Biophys. 168:40-56 (1975).

59. Keith, A. D., R. C. Aloia, J. Lyons, W. Snipes and E. T. Pengelley. Spin label evidence for the role of lysoglycerophosphatides in cellular membranes of hibernating mammals. Biochim. Biophys. Acta 394:204-210 (1975).

60. Cupp, J., M. Klymkowski, J. Sands, A. Keith and W. Snipes. Effect of lipid alky1 chain perturbations on the assembly of bacteriophage PM2. Biochim. Biophys. Acta 389:345-357 (1975).

61. Takayama, K., A. D. Keith and W. Snipes. Effect of isoniazid on the protoplasmic viscosity in Mycobacterium tuberculosis. Antimicrobial Agents and Chemotherapy $7: 22-24(1975)$.

62. Snipes, W., S. Person, A. Keith and J. Cupp. Butylated hydroxytoluene inactivates lipid-containing viruses. Science 188:64-66 (1975).

63. Dalton, L. R., P. Coffey, L. A. Dalton, B. H. Robinson and A. D. Keith. Theory of nonlinear spin response: Rapid passage for very slow molecular reorientation. Phys. Rev. All:488-498 (1975).

64. Lepock, J. R., P. D. Morse II, R. J. Mehlhorn, R. H. Hammerstedt, W. Snipes and A. D. Keith. Spin labels for cell surfaces. FEBS Lett. 60:185-189 (1975).

65. Cupp, J., P. Wanda, A. Keith and W. Snipes. Inactivation of lipid-containing bacteriophage PM2 by butylated hydroxytoluene. Antimicrobial Agents and Chemotherapy 8:608-706 (1975).

66. Keith, A. D. Spin labeling the hydrocarbon phase of biological membranes, in Mitochondria: Bioenergetics, Biogenesis, and Membrane Structure (ed. L. Packer). Academic Press, New York, 1976. pp. 291-302.

67. Hammerstedt, R., R. Amann, T. Rucinsky, P. Morse, J. Lepock, W. Snipes and A. Keith. Use of spin labels and electron spin resonance spectroscopy to characterize membranes of bovine sperm: Effect of butylated hydroxytoluene and cold shock. Biol. of Reprod. 14:381-397 (1976).

68. Henry, S. A., A. D. Keith and W. Snipes. Changes in the restriction of molecular rotational diffusion of water-soluble spin labels during fatty acid starvation of yeast. Biophys. J. 16:641-654 (1976).

69. Wanda, P., J. Cupp, W. Snipes, A. Keith, T. Rucinsky, L. Polish and J. Sands. Inactivation of the enveloped bacteriophage $\Phi 6$ by butylated hydroxytoluene and butylated hydroxyanisole. Antimicrob. Agents Chemother. 10:96-101 (1976).

70. Keith, A. D. and W. Snipes. Biological applications of spin exchange, in Magnetic Resonance in Colloid and Interface Science (eds. H. A. Resing and C. G. Wade) Pp. 426-439. Am. Chem. Soc., Washington, DC, 1976. 
Keith - Bibliography (continued)

71. Snipes, W., S. Person, G. Keller, W. Taylor and A. Keith. Inactivation of lipid-containing viruses by long-chain alcohols. Antimicrob. Agents Chemother. 11:98-104 (1977).

72. Keith, A. D., E. C. Pollard, W. Snipes, S. A. Henry and H. R. Culbertson. Inositol-less death in yeast results in a simultaneous increase in cellular viscosity. Biophys. J. 17:205-212 (1977).

73. Keith, A. D., W. Snipes and D. Chapman. Spin-label studies on the aqueous regions of phospholipid multilayers. Biochemistry 16:634-641 (1977).

74. Keith, A. D. Chemistry of fatty acids. In Enciclopedia della Chimica, Firenza, Italy.

75. Keith, A. D. and W. Snipes. Dynamic aspects of biological membranes. In Horizons in Biochemistry and Biophysics, vol. 4 (ed. E. Quagliariello) (in press)

76. Kruuv, J., J. R. Lepock and A. D. Keith. The effect of fluidity of membrane lipids on freeze-thaw survival of yeast. In press.

77. Keith, A. D., W. Snipes, R. J. Mehlhorn and T. Gunter. Factors restricting diffusion of water-soluble spin labels. Biophys. J. 19:205-218 (1977).

78. Snipes, W., K. Kenny and A. Keith. A spin-reduction assay for lipoxidase. Analyt. Biochem., in press.

79. Keith, A. D., D. Arruda, L. Ruhlig, W. Snipes and A. Verbalis. Spin label studies on the aqueous cytoplasm. In The Aqueous Cytoplasm (ed. A. D. Keith and E. C. Pollard), Marcel Dekker, in press.

80. Keith, A. D. and E. C. Pollard (eds.) The Aqueous Cytoplasm. Marcel Dekker Pub. Co., in press.

Articles submitted:

81. Hammerstedt, R. H., A. D. Keith, W. Snipes, R. P. Amann, D. Arruda and L. C. Griel, Jr. Use of spin labels to evaluate effects of cold shock and osmolality on sperm.

82. Dunson, W. A., M. K. Dunson and A. D. Keith. The nasal gland of the Montpellier snake Malpolon monspessulanus: Fine structure, secretion composition, and a possible role in reduction of dermal water loss.

83. Klip, A., S. Grinstein and A. D. Keith. Exposure of tryptophan residues in sarcoplasmic membranes determined by fluorescence quenching.

84. Hammerstedt, R. H., A. D. Keith, R. C. Boltz, Jr. and P. Todd. Characterization of sperm surfaces: Effect of detergents on ESR signals from surfacedirected spin labels, whole cell isofocusing $\mathrm{pH}$ and metabolic rate.

85. Snipes, W., P. Wanda, G. Keller, S. Person, T. Holland, A. Keith and P. Keller. Effects of butylated hydroxytoluene on Herpes Simplex Virus in vitro.

86. Keith, A. D., D. Arruda, W. Snipes and P. Frost. The antiviral effectiveness of BHT on Herpes cutaneous infections in hairless mice.

In manuscript:

87. Dalton, L. A., B. H. Robinson, L. R. Dalton and P. Coffey, P. W. Percival J. S. Hyde and A. D. Keith. Molecular and applied modulation effects in electron electron double resonance VI: Investigation of mechanisms for electron and nuclear spin-lattice relaxation for ${ }^{14} \mathrm{~N}$ and ${ }^{15} \mathrm{~N}$ spin labels. 
APPENDIX OF SPIN LABEL MEASUREMENTS

Spin-Broadening Agents

Spin labels undergo electron spin exchange in solution. Low frequency near-encounters of spin label molecules result in negligible effects on the resonance line shapes. In concentrations of $10^{-3} \mathrm{M}$ and higher, in water, the near-encounter frequency is high enough that the resonance absorption lines are detectably broadened. Further increases in spin label concentrations continue to broaden absorption lines. Spin label (nitroxides) concentrations can be maintained at $10^{-3} \mathrm{M}$ or lower and the absorption lines can also be broadened by a second paramagnetic species. The second paramagnetic species can be a paramagnetic ion, a paramagnetic chelate complex, or a paramagnetic organic species. We refer to a second paramagnetic species, used to broaden the spin label resonance line, as a Spin-Broadening Agent. Because of the relationship that exists between first-derivative line heights (h) and first-derivative line width (W) in determining the integrated intensity (I) of a spin label signal,

$$
I=k W^{2} \mathrm{~h}
$$

where $k$ is a line shape constant, the line height is reduced rapidly with increased line width.

Because of the relationship given above, it is advaritageous to have the minimum line width of spin labels used for this purpose as narrow as possible. In order to achieve the narrowest linewidths possible, we have carried out syntheses in which the spin labels are totally deuterated. Because the nuclear magnetic moment of deuterium is substantially smaller than that of hydrogen, the minimum linewidths of equivalent spin labels are also considerably more narrow. The net effect of having deuterated 
spin labels allows for the use of lower concentrations of spin-broadening agents than would otherwise be required.

The main biological use of spin-broadening agents is in connection with measuring the properties of the aqueous phase of membrane enclosures. A membrane enclosure may be an artificially produced vesicle or a cell system. The requirements of an interacting spin-broadening agent and a spin label are usually simply that the spin-broadening agent be impermeable to the membrane system and the spin label be permeable. Satisfying these two criteria results in a condition where all the spin label signals can be removed from outside the membrane enclosure while the spin label signal emanating from aqueous zones inside the membrane enclosure is unaffected by the spin-broadening agent. Sometimes it is advantageous to use a spinbroadening agent that has a positive charge such as the nickel ion, and for some conditions it is advantageous to use a spin-broadening agent with a negative charge such as potassium ferricyanide.

The actual concentration dependencies for effective line broadening are somewhat different for each spin-broadening agent. For example, the nickel ion at $10 \mathrm{mM}$ will broaden small water-soluble spin labels by about 1.2 gauss in water at room temperature. Under equivalent conditions, potassium ferricyanide will broaden the resonance lines about 0.7 gauss. Frequently the concentration requirements in vesicle or membrane systems is substantially higher than this. Sometimes it is necessary to use $100 \mathrm{mM}$ nickel concentration in order to achieve line broadening.

The magnitude of line broadening is also viscosity-dependent. As the viscosity of the solution increases, the near-encounter frequency decreases as is expected from diffusion considerations. As the near-encounter 
frequency at a given concentration is reduced by increasing viscosity then a higher concentration of spin-broadening agent is required in order to return the system to the minimum required near-encounter frequency.

Estimation of Ce11 Volume by ESR

Spectral measurements can be made to allow estimation of cell volume (volume protected from spin-broadening agent). The integrated intensity (I) of first derivative spin label signal is given by the equation

$$
I=k W^{2} \mathrm{~h}
$$

where $k$ is a line shape constant, $W$ is the first-derivative line width, and $h$ is the first-derivative line height. The low field line is routinely used for these measurements. Spectra are obtained from cell suspensions and from cell-free medium. The equation used to calculate cell volume is

$$
\text { cell volume }\left(\mu m^{3}\right)=\frac{w_{s}^{2} h_{s} g_{b} 10^{12} \mu m^{3}}{g_{s} w_{b}^{2} h_{b}(\text { sperm/m1 })}
$$

where $s$ is signal from cell suspension broadening agent, $b$ is signal from the cell-free medium without broadening agent, and $g$ is the instrument gain required in each case to make I for the two spectra of equal amplitude.

Effect of Hyper- and Hypoosmotic Media

Washed cells are resuspended in $300 \mathrm{~m} 0 \mathrm{sm}$ buffer containing broadening agent at the concentration required for ESR measurements. Equal volumes of cell suspension and non-isotonic buffer containing 2 H-TEMPONE and broadening agent are mixed. This provides a final suspension with an osmolality between 160 and up to $3000 \mathrm{~m} 0 \mathrm{sm}$. The lower limit is established by the concentration of the broadening agent required for the experiment. Spectra are recorded within $30 \mathrm{~min}$ of sample preparation. Osmolality of 
solutions used is determined or verified by freezing-point depression (Osmette, Precision Systems, Inc.). Curves are fitted to the ESR data and the curve (linear, exponential or logarithmic) giving the best fit is established.

Cellular Cytoplasmic Viscosity

Two sets of measurements are required to establish rotational and translational diffusion properties of cellular protoplasm. These values correspond to measurements of micro- and macroviscosity.

$\tau_{c}$ is a measure of rotational diffusion. Since measurement of $\tau_{c}$ requires motion about rotational axes, the forces that limit molecular motion are evaluated in a volume of protoplasm with dimensions on the order of the diameter of the spin label molecule. Values for $\tau_{c}$ are calculated from spectral measurements using the general method of Kivelson (1960) and the calculations are described in detail elsewhere (Keith et al., 1974). The expression

$$
\tau_{c}=K W_{0}\left[\left(\frac{h_{0}}{h_{-1}}\right)^{\frac{1}{2}}-1\right]
$$

is used for measurements made from deuterated spin label spectra. All $\tau_{c}$ values should be $<10^{-9} \mathrm{sec}$.

Translational diffusion is a measure of linear motion of spin label molecules over distances larger than the average cubic lattice spacing between spin labels. The rate of translational diffusion and the concentration of spin label molecules determine the probability of molecular encounters. The frequency of molecular encounters is proportional to $\Delta H$, the magnitude of concentration-dependent line broadening (Keith et al., 1977).

Classical estimates of diffusion rate depend on measurements made during net flow of solute and give the diffusion constant (D). The diffusion constant for glucose $(M W=180)$ in water at $25^{\circ}$ is $6.67 \times 10^{-6} \mathrm{~cm}^{2} / \mathrm{sec}$ 
(Handbook of Chemistry and Physics, 1970). The diffusion constant of ${ }^{2} \mathrm{H}-$ TEMPONE was found, by the capillary method, to be $7 \times 10^{-6} \mathrm{~cm}^{2} / \mathrm{sec}$ (Menghetti, , unpublished observation).

With spin labels, diffusion rate can be estimated under equilibrium conditions. The estimate of diffusion rate depends on spin exchange occurring by interaction of electronic wave functions of atoms on the periphery of the sphere of rotation of a spin label molecule. The spin labels are not required to physically interact. A general expression relating electron spin exchange frequency $\left(\omega_{e x}\right)$ and spin label molarity $(M)$ to a diffusion constant determined with spin label $\left(D_{S L}\right)$ is

$$
D_{S L}=C\left(\omega_{e x} / M\right)=C(\Delta H / M)
$$

where $C$ is a constant of proportionality and $\omega_{\text {ex }}$ is measured as $\Delta H$ (Keith et al'., 1977). Collision frequency $\left(C_{f}\right)$ can be measured in terms of $\omega_{e x}$. The expression

$$
w_{\text {ex }}=\mathrm{P}_{\mathrm{ex}} \mathrm{C}_{\mathrm{f}}
$$

is established where the probability of an exchange event per collision $\left(\mathrm{P}_{\mathrm{ex}}\right)$ is $\leq 1$ and therefore $\omega_{\mathrm{ex}} \leq \mathrm{C}_{\mathrm{f}}$ (Kivelson, 1957).

At equilibrium, spin label molecules are dispersed throughout the solvent. The idealized cubic lattice spacing(s) for molecules in solution (i.e., the distance between centers, of spin label molecules considered to be in a cubic lattice array) is given by

$$
s=\left(10^{27} \stackrel{\circ}{A}^{3}\right)\left(6.02 \times 10^{23}\right)^{-1}{ }^{1 / 3} \mathrm{M}^{1 / 3}=11.84 \stackrel{\circ}{\mathrm{A}(\mathrm{M})}{ }^{1 / 3} .
$$

Spin label molecules have a constant volume $\left(\sim 300 \AA^{3}\right.$ for ${ }^{2}$ H-TEMPONE, $4.16 \AA$ radius) and doubling the concentration of spin label in solution should double the collision frequency. This relationship is obeyed 
-... and, therefore, measurements of $\mathrm{D}_{\mathrm{SL}}$ by this procedure require correction for spin label molarity.

Values for $\mathrm{D}_{\mathrm{SL}}$ determined in this way measure a diffusion value relating to the pathlength between collisions resulting in spin exchange. When the concentration of spin label is very low, the pathlength is relatively large while at higher concentration the pathlength is smaller. Under equilibrium conditions, the pathlength between collisions $(l)$ is given by

$$
\ell=s\left(V_{T} / V_{S L}\right)^{2 / 3}
$$

where $V_{S L}$ and $V_{T}$ are the volumes occupied by the spin label and the total solution, respectively, and $s$ is the cubic lattice spacing between spin molecules. The volume ratio is related to spin label molarity (M) by

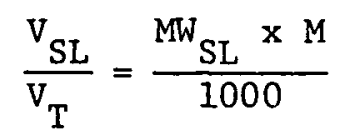

and cubic lattice spacing is related to spin label molarity by Eq. 6 . Therefore, the relationship between mean free path and spin label molarity is approximated by

$$
\ell=1184 \AA / M(M W)^{2 / 3}
$$

Assumptions made are that the density of the spin label is 1.0 and that $\mathrm{V}_{\mathrm{SL}} \ll \mathrm{V}_{\mathrm{T}} \cdot$
Calculations (not presented) of $\mathrm{D}_{\mathrm{SL}}$ using the true physical volume
of ${ }^{2} \mathrm{H}-\mathrm{TEMPONE}$ are in error by a factor of two. Since spin exchange does not require physical collision but rather a close encounter to permit electron wave function interaction, it is logical that the effective volume of the spin label is greater than the physical volume. Increasing $V_{S L}$ by $10-f o l d$ to $3000 \AA$ ( $r$ increased by $2.15 X$ ) results in equivalent values for $D_{S L}$ and $\mathrm{D}$. 
cells with any of these surface spin labels (IV, V, VI) followed by treatment of the cell system with an agent that removes spin from extracellular areas still results in a residual signal of a partially immobilized spin label. The exact localization of the spin label is presently unknown. We plan to carry out experiments using tritiated spin labels and autoradiography on intact mammalian cells in order to determine the localization. It is entirely possible that surface spin labels of the type mentioned may be trapped under proteins on the surfaces of cells or are tightly associated with proteins and may be hindered from the effects of the spin-broadening agents.

We have carried out preliminary experiments to illustrate the feasibility of obtaining useful information about cell surfaces from charged spin labels. For example, the experiment described in the main body of this proposal where varying quantities of negatively charged phospholipids are added to vesicles of dimyristoyl lecithin illustrate that surface charge on vesicles can be detected in a very sensitive manner. We believe that this basic observation can be useful in cell systems and that it can be expanded to determine a good deal more about cell surfaces.

\section{Literature Cited:}

Kivelson, D. Theory of ESR linewidths of free radicals. J. Chem. Phys.

33: $1094-1106(1960)$.
Keith, A. D., D. Horvat and W. Snipes. Spectral characterization of ${ }^{15} \mathrm{~N}$ spin labels. Chem. Phys. Lipids 13:49-62 (1974).

Keith, A. D., W. Snipes, R. J. Mehlhorn and T. Gunter. Factors restricting diffusion of water-soluble spin labels. Biophys. J., in press.

Kivelson, D. Theory of the effects of exchange on the nuclear fine structure in the paramagnetic resonance spectra of liquids. J. Chem. Phys 27:10871088 (1957).

Lepock, J. R., P. D. Morse II, R. J. Mehlhorn, R. H. Hammerstedt, W. Snipes and A. D. Keith. Spin labels for cell surfaces. FEBS Lett. 60:185189 (1975). 
COO-2223-25

TABLE OF CONTENTS

of Enclosures

Reprint: Spin Label Studies on the Aqueous Regions of Phosphorlipid Multilayers. A. D. Keith, W. Snipes and D. Chapman (previously sent ass preprint)

Reprint: Inositol-less Death in Yeast Results in a Simultaneous Increase in Intracellular Viscosity. A. D. Keith, E. C. Pollard, W. Snipes, S. A. Henry and M. R. Culbertson.

Reprint: Factors Restricting Diffusion of Water-Soluble Spin Labels. A. D. Keith, W. Snipes, R. J. Mehlhorn and T: Gunter.

Preprint: A Spin-Reduction Assay for Lipoxidase. W. Snipes, K. Kenny and A. Keith.

Preprint: Spin Label Studies on the Aqueous Cytoplasm. A. D. Keith, D. Arruda, L. Ruhlig, W. Snipes and A. Verbalise.

In The Aqueous Cytoplasm (eds. A. Keith and E. C. Pollard) Marcel Dekker, in press.

Preprint: Use of Spin Labels to Evaluate Effects of Cold Shock and Osmolality on Sperm. R. H. Hammerstedt, A. D. Keith, W. Snipes, R. P. Amon, D. Arruda, L. C. Griel, Jr. (submitted for publication)

Reprints of

Preprents

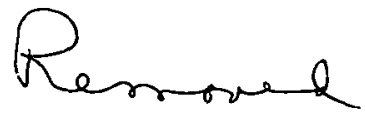

